\title{
Advances in Materials
}

\section{Structural, Optical and Magnetic Properties of (Ni, Al) Co-Doped ZnO Nanoparticles}

\author{
Peyyala Swapna, Sakirevupalli Venkatramana Reddy*
}

Department of Physics, Sri Venkateswara University, Tirupati, India

Email address:

drsvreddy123@gmail.com (S. V. Reddy)

${ }^{*}$ Corresponding author

\section{To cite this article:}

Peyyala Swapna, Sakirevupalli Venkatramana Reddy. Structural, Optical and Magnetic Properties of (Ni, Al) Co-Doped ZnO Nanoparticles. Advances in Materials. Vol. 8, No. 1, 2019, pp. 1-11. doi: 10.11648/j.am.20190801.11

Received: December 26, 2018; Accepted: January 21, 2019; Published: February 13, 2019

\begin{abstract}
We synthesize pure and $(\mathrm{Ni}, \mathrm{Al})$ co-doped Zinc Oxide $(\mathrm{ZnO})$ nanoparticles by chemical co-precipitation method at room temperature successfully using poly ethylene glycol (PEG) as stabilizing agent. In the preparation, we kept one dopant element aluminum at constant concentration, $5 \mathrm{~mol} \%$ by varying the other dopant concentration from one to three mol\%. Following the completion of synthesis, the nanopowders are cautiously subjected to diverse characterizations such as XRD, SEM with EDS, TEM, PL, UV-Vis-NIR, Raman and VSM to determine the properties to be found the structural, optical and magnetic. XRD data shows that all the nanopowder samples acquire hexagonal wurtzite crystal structure by means of no secondary phases connecting to aluminum or nickel; this indicates the well dissolution of aluminum and nickel in to $\mathrm{ZnO}$ host lattice. The exact size of particles is predicted using TEM illustrations, which are more or less confirmed by the XRD data. The morphology of the samples is identified using SEM images, and EDS spectrum reveals that no impurities are present in the powder samples than nickel and aluminum. Optical properties are deliberated via PL spectrum and UV-Vis-NIR spectra, every one of the samples have defect related peaks in the visible region. Magnetic properties are estimated by means of the technique VSM, except pure $\mathrm{ZnO}$ nanoparticles remaining all the doped samples contains the Ferro magnetic nature.
\end{abstract}

Keywords: Spintronics, Optoelectronics, DMS, Chemical Co-Precipitation, RTFM

\section{Introduction}

In the recent years, semiconductor nanomaterials comprise fascinated large attraction owing to their significant technical, scientific and industrial applications, for instance Optoelectronics, Photonic devices, nanoelectronics and storage devices [1-5]. Zinc Oxide is a wide band gap (3.37 $\mathrm{eV})$ semiconductor having great binding energy $(60 \mathrm{meV})$ by wurtzite crystal structure encompassing of large optical gain at room temperature via strange distinctive spintronics and photonic properties [6-9]. Recently $\mathrm{ZnO}$ based Dilute magnetic semiconductors had been concentrating on a novel practical technologies such as spin - electronics or spintronics [10-12]. Dilute magnetic semiconductors are semiconducting alloys by spin carriers in accumulation to charge carriers while adding of degrees of freedom in a particular substance synthesized through dilute replacement of transition metal ions semiconductor host material. Quite a lot of methods are existing for the synthesis of Zinc Oxide nanostructures for instance physical methods and chemical methods. A few methods are Solution combustion method [13], DC thermal plasma method [14], Sputtering method [15], Sol-gel method, Chemical vapor deposition (CVD) [16], and Chemical co-precipitation [17-20]. Out of all these methods, we selected chemical co-precipitation method for the synthesis of Zinc Oxide ( $\mathrm{ZnO}$ ) nanoparticles owing to its less cost, large uniformity and substantial yield of nanoparticles. In the current work $\mathrm{ZnO}$ and $(\mathrm{Ni}, \mathrm{Al})$ co-doped $\mathrm{ZnO}$ nanoparticles are productively synthesized at room temperature by poly ethylene glycol (PEG) as stabilizing agent.

\section{Experimental Section}

\subsection{Synthesis}

For the synthesis of pristine and $(\mathrm{Ni}, \mathrm{Al})$ co-doped Zinc 
Oxide nanoparticles, zinc acetate de hydrate $\left(\mathrm{Zn}\left(\mathrm{CH}_{3} \mathrm{COO}\right)_{2}\right.$ $\left.2 \mathrm{H}_{2} \mathrm{O}\right)$, potassium hydroxide $(\mathrm{KOH})$, are used as starting materials and nickel chloride, aluminum nitrate nano hydrate $\left(\mathrm{Al}\left(\mathrm{NO}_{3}\right)_{3} .9 \mathrm{H}_{2} \mathrm{O}\right)$ are selected as doping materials. All the chemicals are analytical grade and prone without ancillary purification. To synthesize pristine and (Ni, Al) co-doped Zinc Oxide nanoparticles of $0.2 \mathrm{M}$ solution, Zinc acetate de hydrate $\left(\mathrm{Zn}(\mathrm{CH} 3 \mathrm{COO})_{2} 2 \mathrm{H}_{2} \mathrm{O}\right)$, is dissolve in de-ionized water, potassium hydroxide solution is consequently supplemented drop by drop at stable stirring of $10 \mathrm{hrs}$ to form white precipitate. Aluminum nitrate nano hydrate (Al $\left.\left(\mathrm{NO}_{3}\right)_{3} .9 \mathrm{H}_{2} \mathrm{O}\right)$ and nickel chloride solutions are merged through the above solution, in drops to synthesize $(\mathrm{Ni}, \mathrm{Al})$ co-doped Zinc Oxide nanoparticles. By decontaminating the formed Precipitate via the process of filtration and cleansed much more number of times using de-ionized water, surplus chemical species created for the duration of the process of synthesis are detached. Then all the samples are dried at $70^{\circ} \mathrm{C}$ for $9 \mathrm{hrs}$ and grind the powder samples finely with the help of agate mortar. At the end all the samples are annealed in the furnace at $500^{\circ} \mathrm{C}$ for 1 hour.

\subsection{Characterizations}

The synthesized samples are carefully subjected to the following characterizations. Powder X-Ray Diffraction (XRD) pattern is recorded on Bruker diffracto meter within $2 \theta$ range of $20^{\circ}$ to $80^{\circ}$ via $\mathrm{CuK} \alpha$ as $\mathrm{X}$-ray source $(\lambda=$ $1.53906 \AA$ ). The surface morphology and chemical analysis of pure and co-doped Zinc Oxide nano powders are calculated by SEM through EDS (model CARL-ZEISS
EVOMA 15). The properties obtained by XRD are corroborated by Transmission electron microscopy (TEM) (Model: philips CM200) and high resolution TEM (Model: Tecnai G2, F30). UV-Vis-NIR (Varian model: 5000), Raman spectroscopy is carried out by (Model: STR $500 \mathrm{~mm}$ ) Focal length Laser Raman spectrometer Photoluminescence studies were carried out by PL spectrometer (Model: FLS980 spectrometer) with a $450 \mathrm{w}$ Xenon arc lamp used as an excitation source. Magnetic properties are studied by the use of the technique Vibrating sample magnetometer (VSM).

\section{Results and Discussions}

\subsection{Structural Properties}

\subsubsection{XRD Analysis}

The XRD images of pristine and $(\mathrm{Ni}, \mathrm{Al})$ co-doped $\mathrm{ZnO}$ nanostructures are shown in the figure 1 . The diffraction peaks of all the concentrations correlate to hexagonal wurtzite crystal phase of Zinc Oxide and the positions of all the diffracted peaks are consistent with the pattern of (JCPDS CARD NUMBER: 36-1451). Lack of secondary phases reveals absence of impurity phases involving aluminum or nickel within the detection limit of the instrument. The peaks concerning to co-doped Zinc Oxide shows high intensity in view of the pure Zinc Oxide nanoparticles. From this we can deliberate that doping of nickel in the increased concentration into Zinc Oxide the intensity of diffracted peak is accessible high. By enhancing the concentration of nickel into $\mathrm{ZnO}$ diffracted peaks shifting towards higher wavelength.

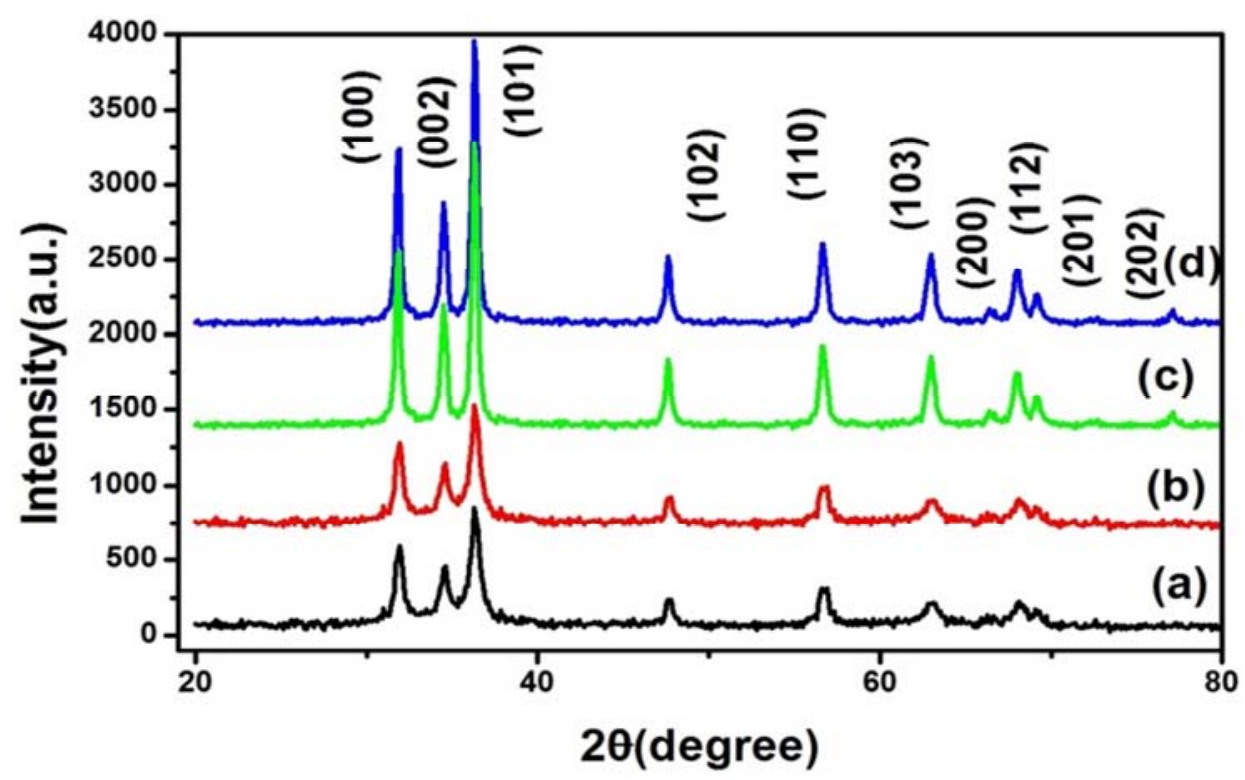

Figure 1. XRD illustration of (a) Pristine ZnO (b) 1 mol\% (c) 2 mol\% (d) 3 mol\% of Ni doped ZnO nanoparticles ( By Keeping Aluminum = 5.0 mol\% as constant).

The size of crystallite is calculated through the Debyescherer formula $d=0.91 \lambda / \beta \cos \theta$, where ' $d$ ' is the crystallite size, ' $\lambda$ ' is the wavelength of the X-rays and ' $\theta$ ' is the Bragg's angle of diffracted rays. The calculated crystallite sizes of pristine and co-doped Zinc Oxide are in the range of
21-19 nm. As of the calculations of diffracted peaks, we found the nanoparticle size decreases by the increased nickel concentration. It is illustrious that as of XRD pattern, codoped Zinc Oxide nanoparticles have large crystalline nature compared to pristine Zinc Oxide sample. 


\subsubsection{Raman Analysis}

Raman spectroscopy is the best technique for estimating the inclusion of dopant elements, defects and chaos in a lattice of a host lattice [21]. Regarding the doped nanostructures, surface is altered owing to charge transport linking the host lattice and dopant element; here it alters the optical Raman spectrum [22]. Figure 2 shows the Raman spectra of pure Zinc Oxide nanoparticles and Figure 3 shows the Raman spectra of $(\mathrm{Ni}, \mathrm{Al})$ co-doped Zinc Oxide nanoparticles. Regarding Pure $\mathrm{ZnO}$, the peaks appeared at $158 \mathrm{~cm}^{-1}, 331 \mathrm{~cm}^{-1}, 580 \mathrm{~cm}^{-1}$ are ascribed to the first and second order vibration modes of Zinc Oxide nanoparticles [23]. The Raman spectra of pure and co-doped samples show the Raman intensive peak at $437 \mathrm{~cm}^{-1}$, which is a higher frequency $\left(\mathrm{E}_{2 \mathrm{H}}\right)$ mode. Additional Raman peaks found at about $330 \mathrm{~cm}^{-1}$ and $832 \mathrm{~cm}^{-1}$ might be attributed to multi phonon modes $\mathrm{E}_{2 \mathrm{H}}-\mathrm{E}_{2 \mathrm{~L}}$ and $\left(\mathrm{A} 1(\mathrm{TO})+\mathrm{E}_{2 \mathrm{~L}}\right)$ correspondingly, where as the Raman intensive peak observed at $882 \mathrm{~cm}^{-1}$ is ascribed to $\mathrm{Zn}-\mathrm{O}-\mathrm{Zn}$ vibration mode. In the range of 1,050 $\mathrm{cm}^{-1}$ to $1130 \mathrm{~cm}^{-1}$ second order vibrations might have been found [24].

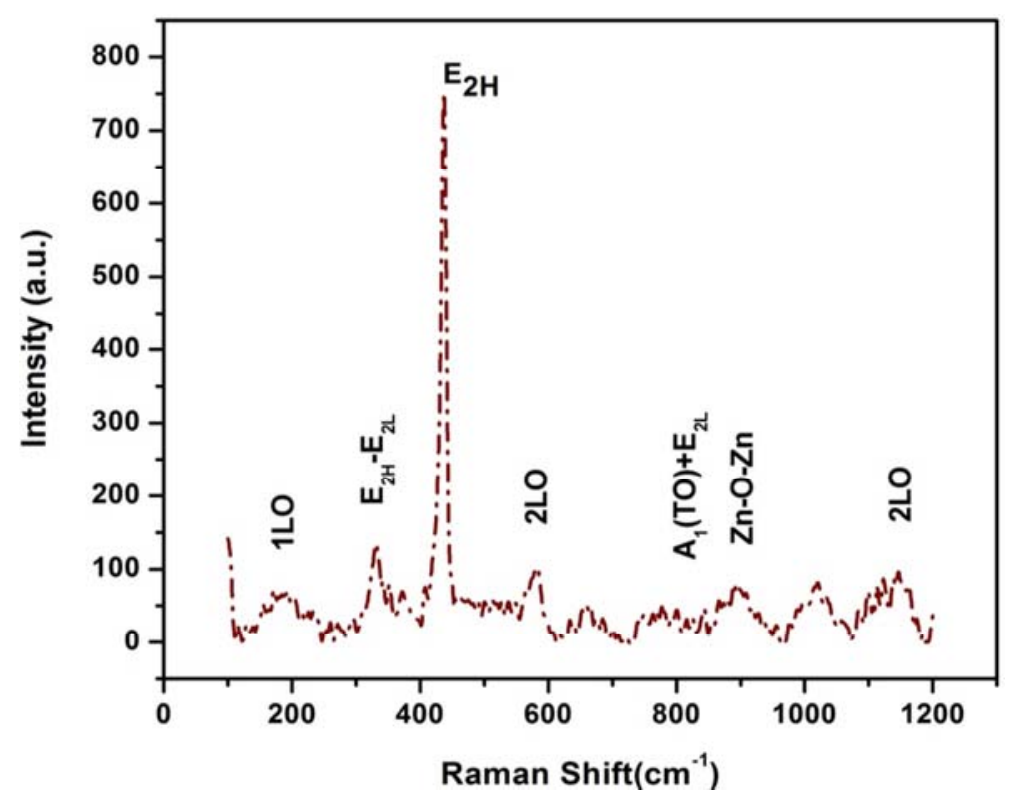

Figure 2. Raman spectra of (a) Pristine $\mathrm{ZnO}$.

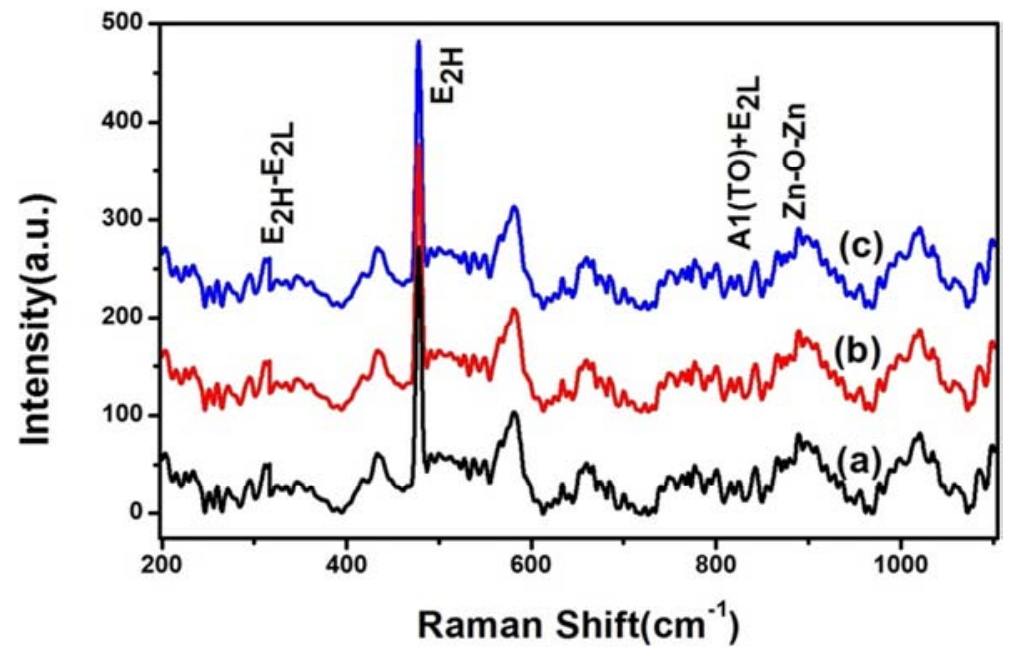

Figure 3. Raman spectra of (a) 1 mol\% (b) 2 mol\% (c) 3 mol\% of Ni doped ZnO nanoparticles (Here Al = 5.0 mol\% is kept as constant).

\subsection{Morphological and Compositional Analysis}

\subsubsection{SEM and EDAX Analysis}

Scanning electron microscopy (SEM) is prone to evaluate the morphology of pristine and $(\mathrm{Ni}, \mathrm{Al})$ co-doped Zinc Oxide nanoparticles. The illustration of the pristine $\mathrm{ZnO}$ nano particles reveals a smaller amount of agglomeration where as co-doped $\mathrm{ZnO}$ samples reveal huge agglomeration by increasing the nickel concentration as given in figure 4. All the pictures are plainly representing the non homogeneous spherical and irregular shape of the nanoparticles. EDS spectrum indicates the integration of dopant elements into Zinc Oxide host lattice, it obviously shows the presence of impurity elements such as nickel and aluminum and non 
existence of other impurities in $\mathrm{ZnO}$ host lattice as shown in figure 5. The EDS spectrum of pristine $\mathrm{ZnO}$ reveals only
Zinc and oxygen elements. Weight and atomic percent of zinc, oxygen, nickel and aluminum are mentioned in table 1.
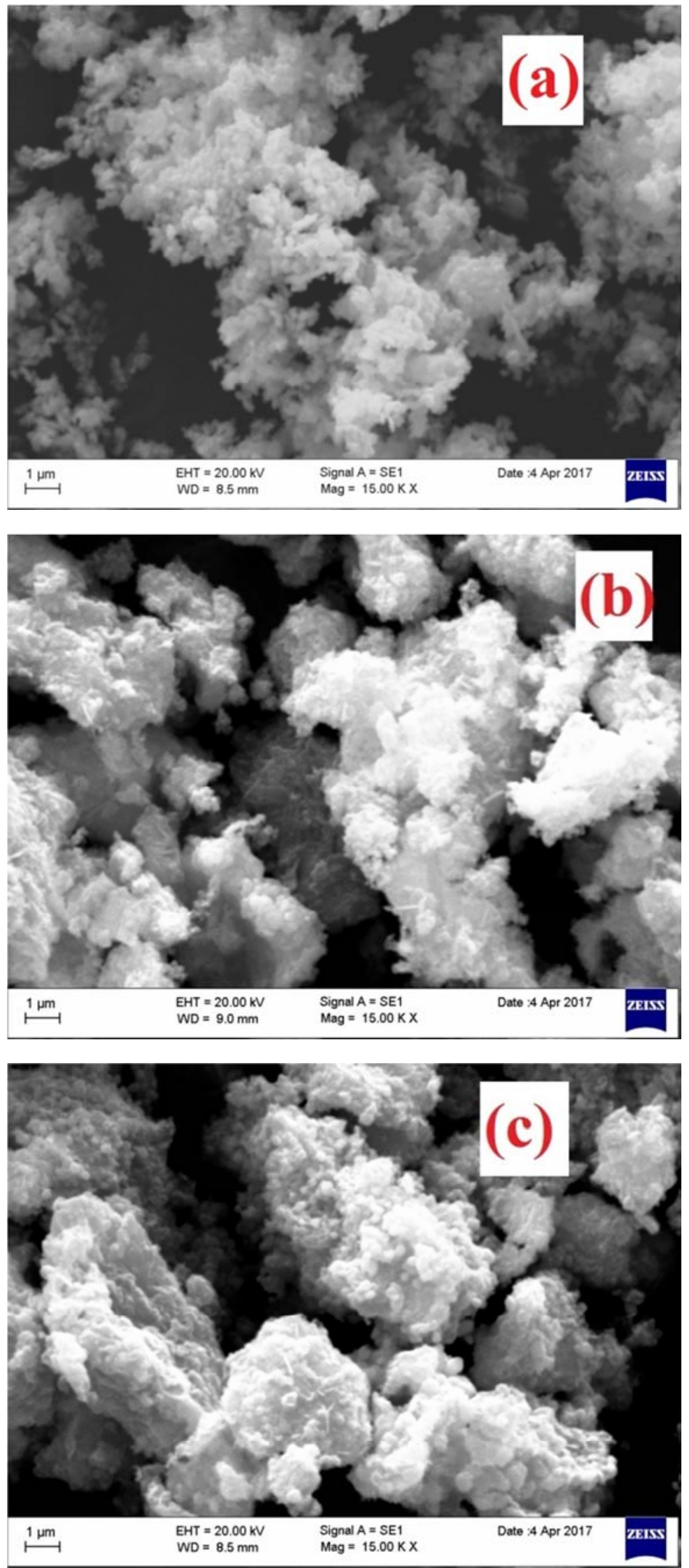


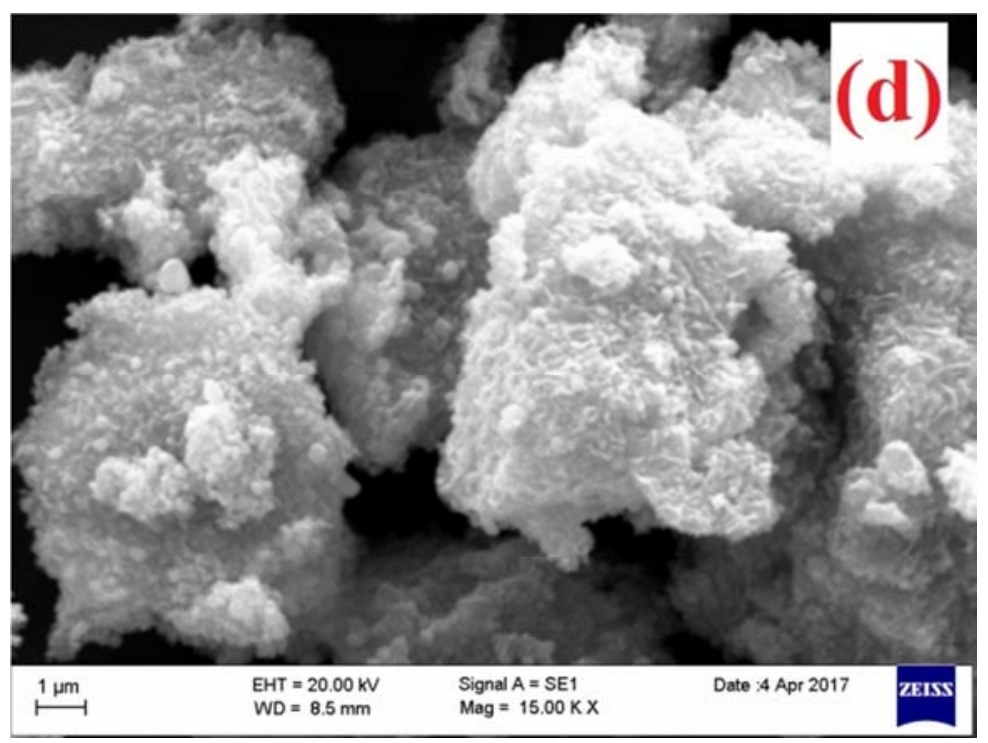

Figure 4. SEM images of (a) UndopedZnO (b) $1 \mathrm{~mol} \%$ (c) $2 \mathrm{~mol} \%$ (d) 3 mol\% of Ni doped ZnO nanoparticles (Here Al = 5.0 mol\% is kept as constant).
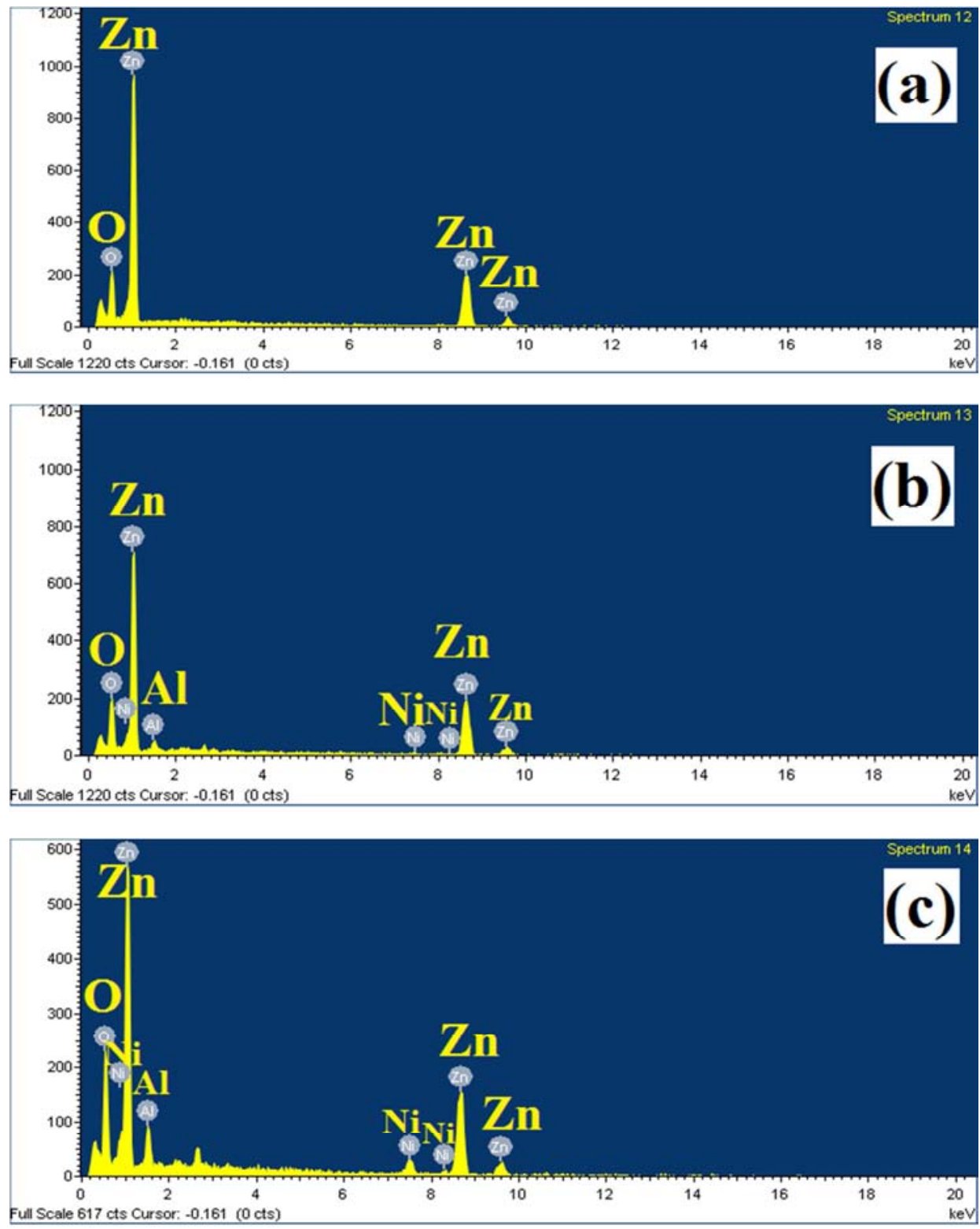


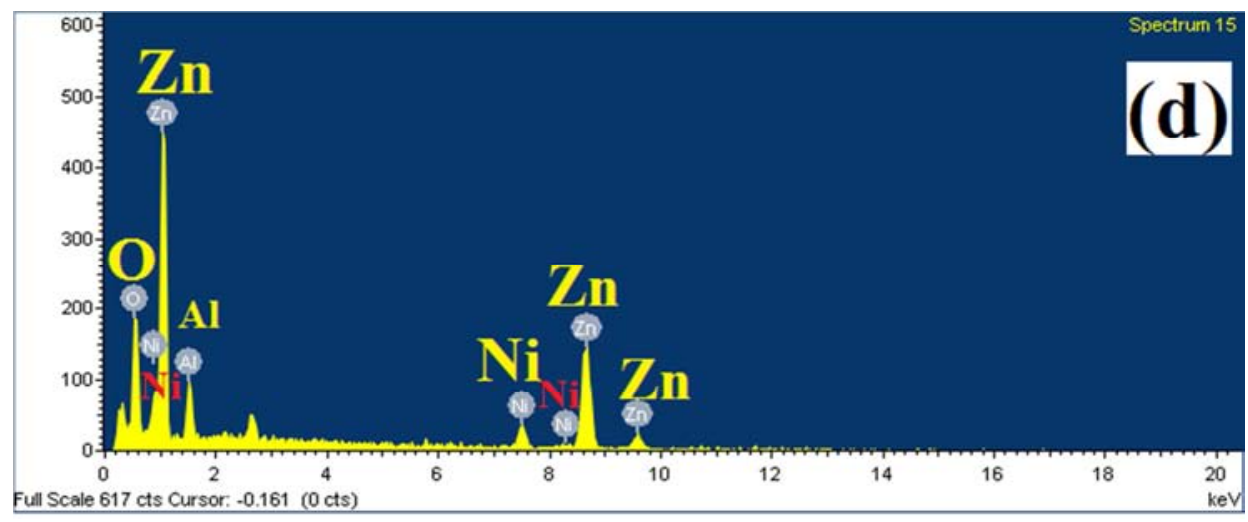

Figure 5. EDS spectrum of (a) Un doped $\mathrm{ZnO}$ (b) 1 mol\% (c) $2 \mathrm{~mol} \%$ (d) $3 \mathrm{~mol} \%$ of Ni doped $\mathrm{ZnO}$ nanoparticles (Here Al = 5.0mol\% is kept as constant).

Table 1. Shows the weight and atomic percent of $\mathrm{Zn}, \mathrm{O}$, Ni and $\mathrm{Al}$.

\begin{tabular}{lllllllll}
\hline \multirow{2}{*}{ Sample } & Zn & \multicolumn{3}{c}{ O } & & Ni & & Al \\
\cline { 2 - 8 } & Weight\% & Atomic\% & Weight\% & Atomic\% & Weight\% & Atomic\% & Weight\% & Atomic\% \\
\hline Pure ZnO & 59.88 & 26.76 & 40.12 & 73.24 & - & - & - & - \\
Ni-1, Al-5 mol\% & 73.03 & 41.53 & 23.39 & 54.34 & 1.09 & 0.69 & 2.49 & 3.43 \\
Ni-2, Al-5 mol\% & 63.62 & 33.85 & 25.57 & 55.57 & 4.81 & 2.85 & 6.00 & 7.74 \\
Ni-3, Al-5 mol\% & 61.47 & 32.87 & 24.53 & 53.60 & 6.58 & 3.92 & 7.41 & 9.60 \\
\hline
\end{tabular}

\subsubsection{Tem, Hrtem and Saed Analysis}

Transmission electron microscopy (TEM) is experienced to evaluate the accurate size of the pristine and co-doped Zinc Oxide nanoparticles. Figure 6 shows the TEM illustrations of pristine and $(\mathrm{Ni}, \mathrm{Al})$ co-doped $\mathrm{ZnO}$ nanoparticles. The size of nanoparticles determined by TEM images are approximately confirmed by the XRD data. Figure 7 shows the HRTEM images and SAED pattern of pristine and co-doped $\mathrm{ZnO}$ nanoparticles. HRTEM picture of the pure $\mathrm{ZnO}$ shows the $5 \mathrm{~nm}$ clear lattice fringes whereas co-doped sample shows $2 \mathrm{~nm}$ clear lattice fringes. SAED pattern of pure and co-doped $\mathrm{ZnO}$ nanoparticles are coincided with the XRD data.
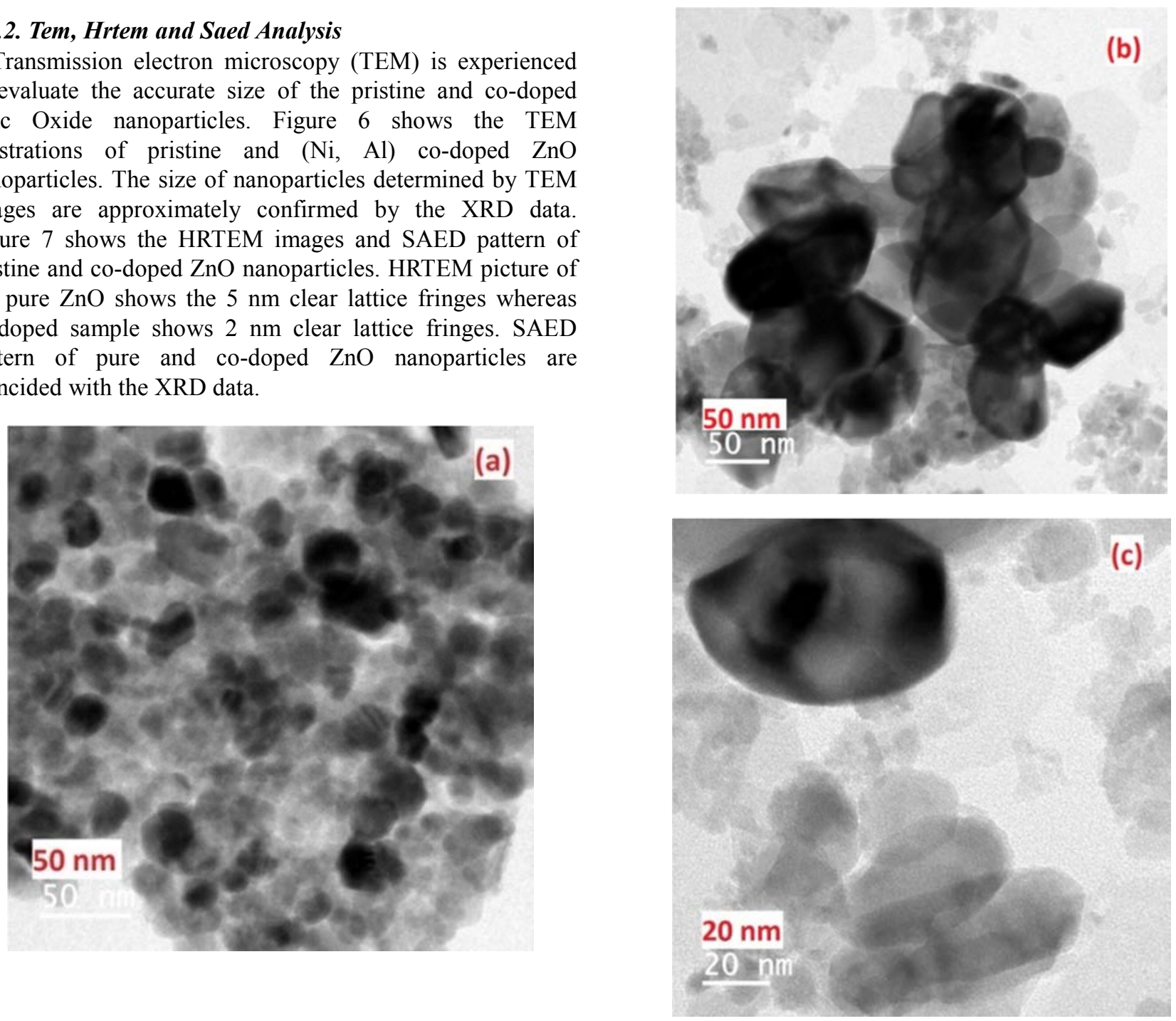


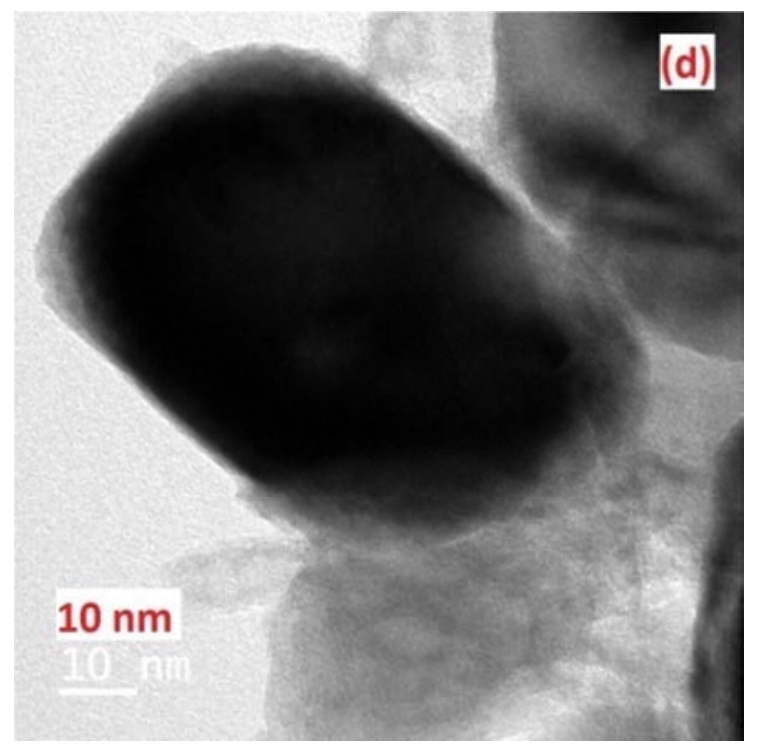

Figure 6. TEM images of (a) Undoped $\mathrm{ZnO}$ (b) 1 mol\% (c) $2 \mathrm{~mol} \%$ (d) 3 mol\% of $\mathrm{Ni}$ doped $\mathrm{ZnO}$ nanoparticles (By keeping $\mathrm{Al}=5.0 \mathrm{~mol} \%$ as constant).
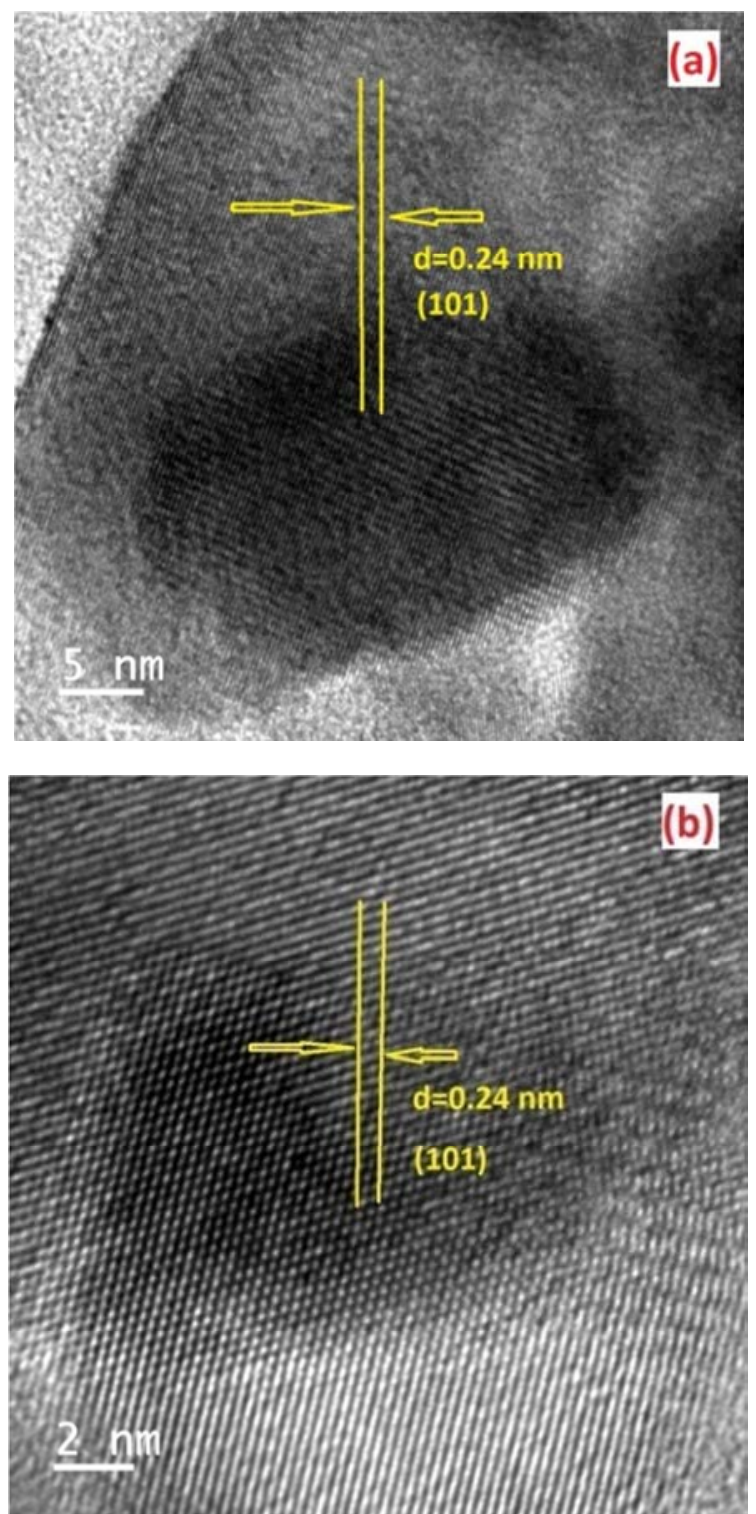
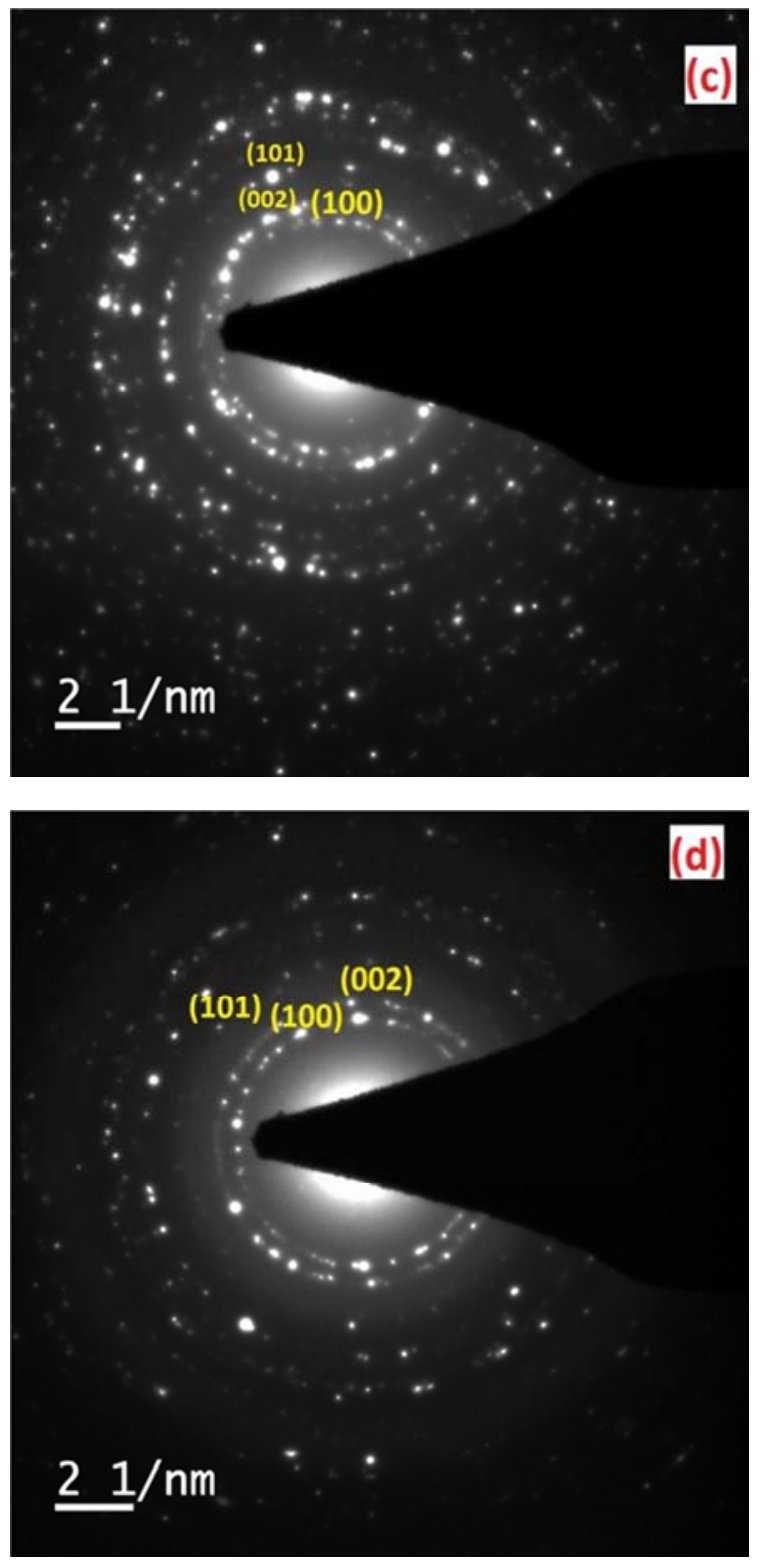

Figure 7. HRTEM images of (a) Pure $\mathrm{ZnO}$ (b) 3 mol\% of Ni doped $\mathrm{ZnO}$ nanoparticles, SAED pattern of (c) Pure $\mathrm{ZnO}$ (d) 3 mol\% of Ni doped ZnOnano particles (By keeping $\mathrm{Al}=5.0 \mathrm{~mol} \%$ as constant).

\subsection{Optical Properties}

\subsubsection{Photoluminescence (PL) Studies}

Photo luminescence spectroscopy (PL) is prone to analyse the emission nature of pristine and $(\mathrm{Ni}, \mathrm{Al})$ co-doped nanoparticles recorded at room temperature in the region of $400 \mathrm{~nm}$ to $750 \mathrm{~nm}$ as shown in figure 8. All the emission peaks are found in the visible range. The peaks are appeared at $436 \mathrm{~nm}, 462 \mathrm{~nm}, 480 \mathrm{~nm}, 492 \mathrm{~nm}, 547 \mathrm{~nm}$, and the broad peak appeared from $580 \mathrm{~nm}$ to $636 \mathrm{~nm}$ centered at $609 \mathrm{~nm}$. The peaks found at $436 \mathrm{~nm}, 462 \mathrm{~nm}, 480 \mathrm{~nm}$ are blue emission peaks and the origin of blue emission in $\mathrm{ZnO}$ is due to oxygen vacancies (Vo) $[25,26]$. The peaks appeared at 492 $\mathrm{nm}, 547 \mathrm{~nm}$ are green emission peaks, which can be ascribed to impurities compatible by means of single ionized vacancy of Oxygen in $\mathrm{ZnO}$ nanoparticles [18, 27-28]. The broad 
emission band appeared from $580 \mathrm{~nm}$ to $636 \mathrm{~nm}$ centered at $609 \mathrm{~nm}$ is in the region of Yellow, Orange and Red and reports the peaks which might occur in the visible region belongs to origin of defects such as oxygen vacancies (Vo) and intrinsic defects ( $\mathrm{Zni})$ in Zinc Oxide $(\mathrm{ZnO})$ nanoparticles [27].

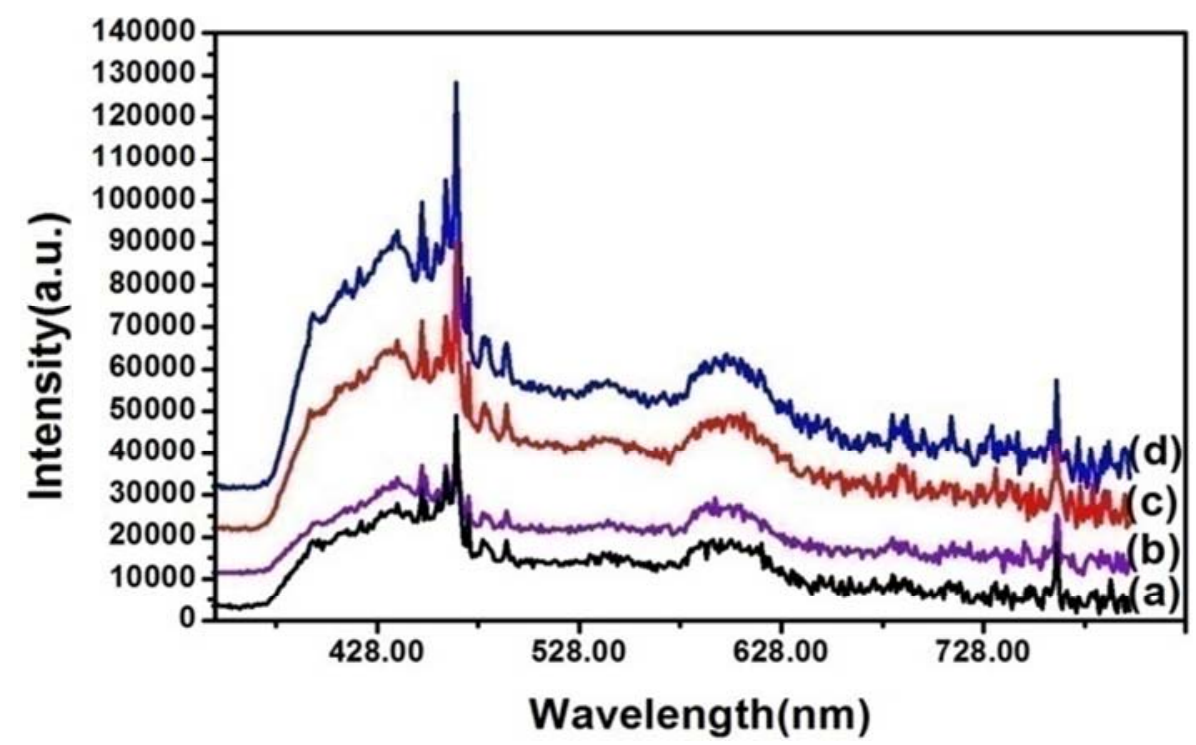

Figure 8. PL spectra of (a) Undoped ZnO (b) 1 mol\% (c) 2 mol\% (d) 3 mol\% of Ni doped ZnO nanoparticles (Here Al=5.0 mol\% is kept as constant).

\subsubsection{UV-Vis-NIR Analysis}

The optical absorption of the pristine and co-doped Zinc Oxide nanopowders is characterized by UV-Vis-NIR in the wavelength region of 200-800 $\mathrm{nm}$. In the UV-Vis-NIR DRS spectrum, there is a slightly shifting in the absorption edges of codoped nanoparticles towards lower wavelength region comparing to pure ZnO. Figure 9 shows the diffuse reflectance spectra of Pure and co-doped nanopowders and shows the characteristic absorption edge in the vicinity of $375 \mathrm{~nm}$.

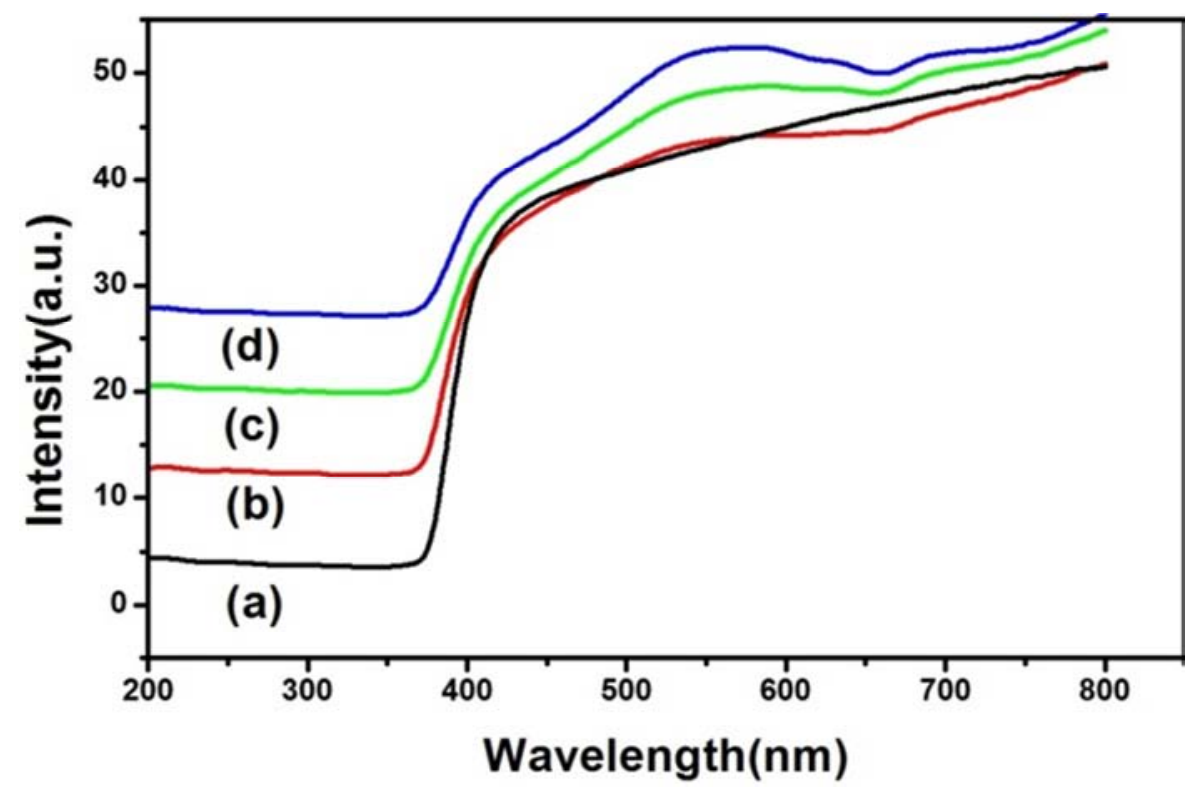

Figure 9. Diffuse reflectance spectra of (a) Un doped ZnO (b) 1 mol\% (c) 2 mol\% (d) 3 mol\% of Ni doped ZnOnano particles (Here Al = 5.0 mol\% is kept as constant).

\subsection{Magnetic Properties}

Room temperature magnetization curves of ( $\mathrm{Ni}, \mathrm{Al})$ codoped $\mathrm{ZnO}$ nanoparticles are shown in the figure10. Pure $\mathrm{ZnO}$ shows diamagnetic nature as we not mentioned in the graph, it is familiar that pristine bulk $\mathrm{ZnO}$ is diamagnetic however, recent reports showed that pristine Zinc Oxide might show ferromagnetic nature under certain film thickness [29], some others also reported Room temperature ferromagnetism (RTFM) in pure Zinc Oxide [30, 31]. This may be attributed to vacancy associated defects which might induce a magnetic moment in the insulator, here in this work doped $\mathrm{ZnO}$ samples keeping $\mathrm{Al}$ as constant at $5 \mathrm{~mol} \%$ and varying the concentrations of nickel from $1 \mathrm{~mol} \%$ to $3 \mathrm{~mol} \%$ 
shows the Ferromagnetic nature. By enhancing the concentration of nickel from $1 \mathrm{~mol} \%$ to $3 \mathrm{~mol} \%$, the Saturation Magnetization (Ms) and Retentivity (Mr) values decreases and Coercitivity $(\mathrm{Hc})$ values increases. Saturation
Magnetization (Ms), Retentivity (Mr) and Coercitivity (Hc) values of all the doping concentrations of nickel are given in the table 2 .

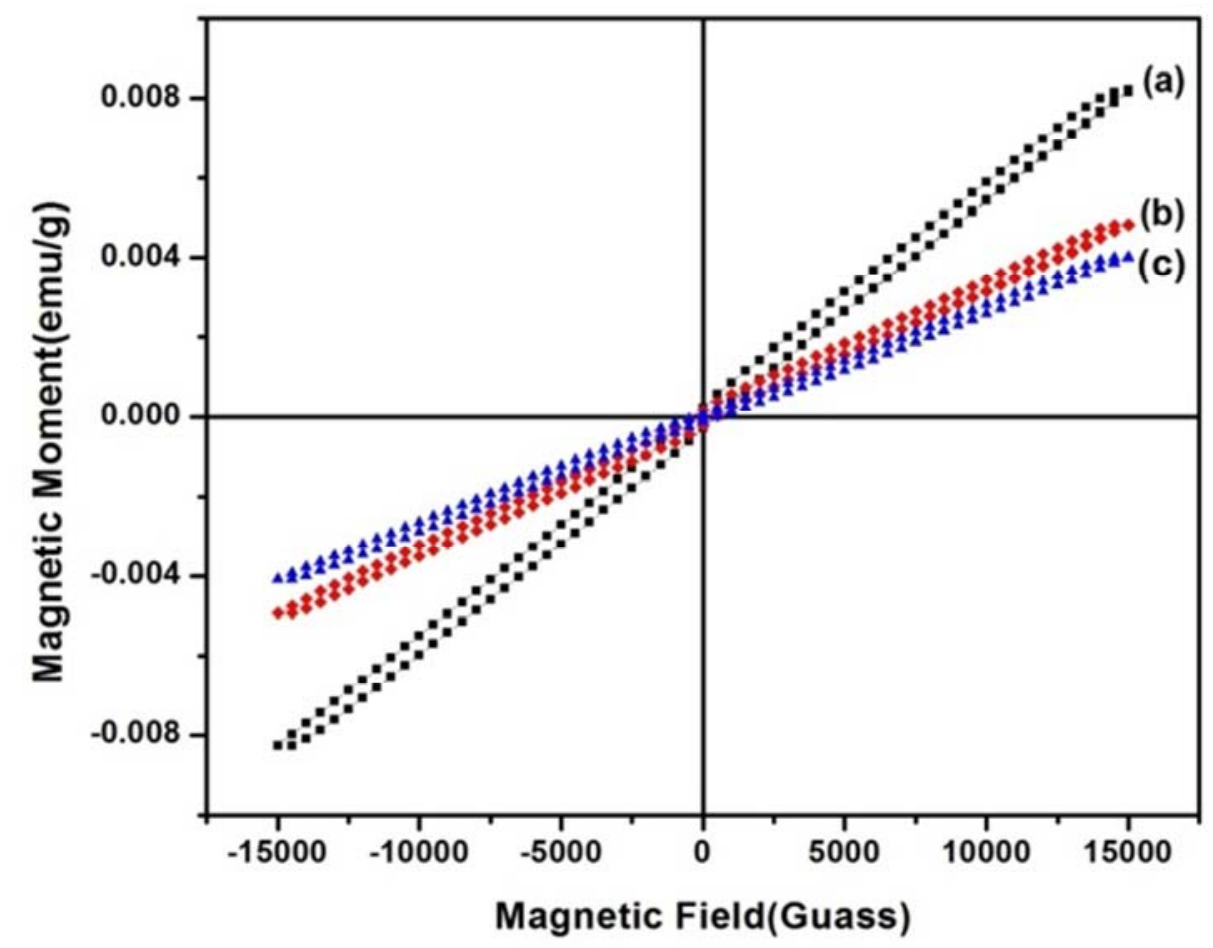

Figure 10. Room temperature M-H curves of (a) 1 mol\% (b) $2 \mathrm{~mol} \%$ (c) 3 mol\% of Ni doped ZnO nanoparticles (Here Al = 5.0 mol\% is kept as constant).

Figure 11 shows Room temperature (RT) M-H curves of co-doped $\mathrm{ZnO}$ nanoparticles in the low field region, which is expanded. The $1 \mathrm{~mol} \%$ of nickel shows highest $\mathrm{Ms}$ and $\mathrm{Mr}$ values compared to remaining concentrations.

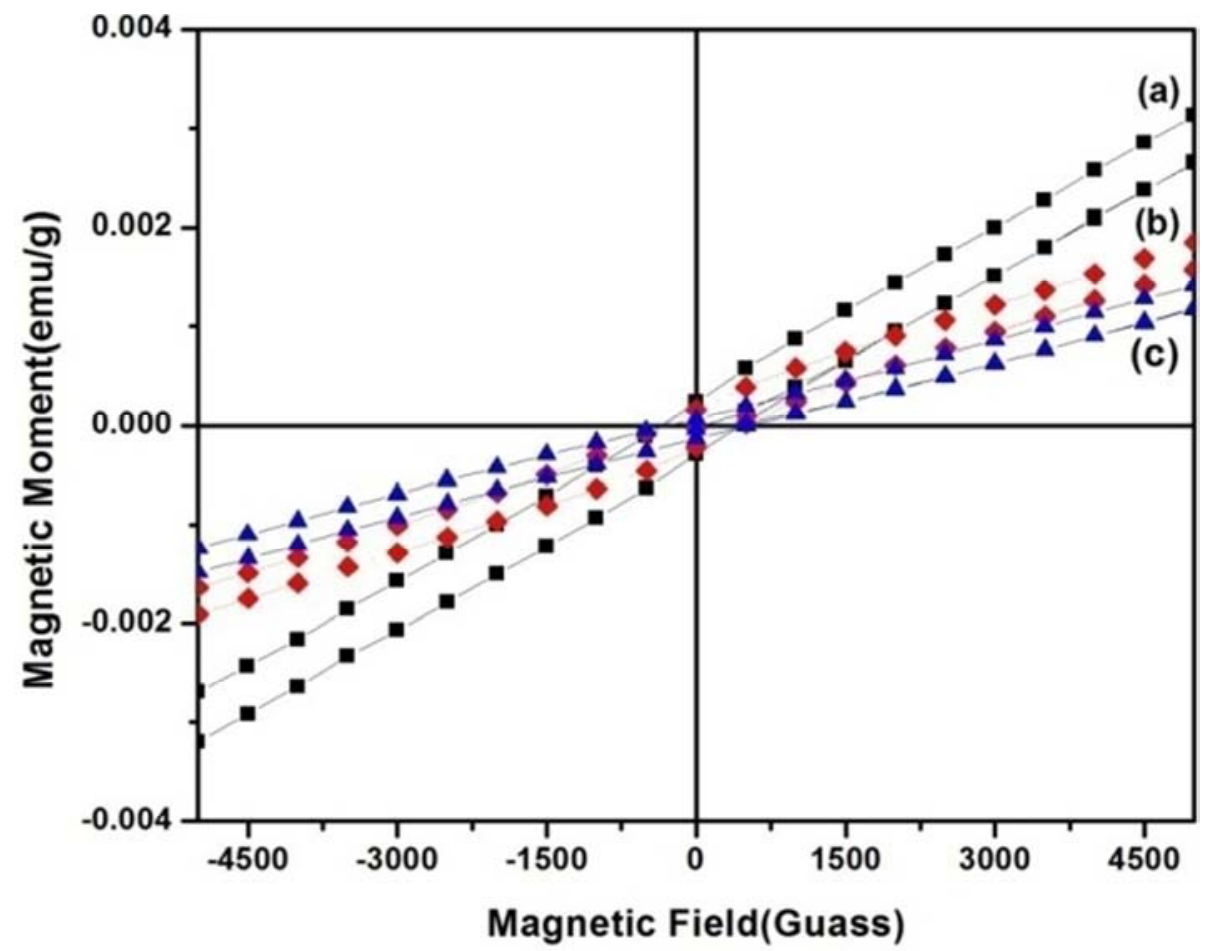

Figure 11. (RT) M-H curves of expanded lower field region of (a) $1 \mathrm{~mol} \%$ (b) $2 \mathrm{~mol} \%$ (c) $3 \mathrm{~mol} \%$ of Ni doped ZnO nano particles (Here Al = $5.0 \mathrm{~mol} \%$ is kept as constant). 
Table 2. Shows Coercivity (Hc), Retentivity (Mr) and Saturation magnetization (Ms) values for (Ni, Al) co-doped ZnO nanoparticles.

\begin{tabular}{llll}
\hline Sample & Magnetization (Ms) (emu) & Coercitivity (Hc) (Guass) & Retentivity (Mr) (emu) \\
\hline $\mathrm{Ni}-1, \mathrm{Al}-5 \mathrm{~mol} \%$ & $8.3261 \times 10^{-3}$ & 389.99 & $259.93 \times 10^{-6}$ \\
$\mathrm{Ni}-2, \mathrm{Al}-5 \mathrm{~mol} \%$ & $4.9945 \times 10^{-3}$ & 389.98 & $195.22 \times 10^{-6}$ \\
$\mathrm{Ni}-3, \mathrm{Al}-5 \mathrm{~mol} \%$ & $4.1125 \times 10^{-3}$ & 411.12 & $113.23 \times 10^{-6}$ \\
\hline
\end{tabular}

\section{Conclusions}

Pristine and co-doped $\mathrm{ZnO}$ nanostructures are synthesized effectively by means of chemical co-precipitation method using PEG as stabilizing agent at room temperature. The synthesized samples are characterized through XRD, SEM with EDS, TEM, HRTEM, SAED pattern, PL, UV-Vis-NIR and VSM techniques and deliberate different kind of properties such as structural, morphological, compositional, optical and magnetic. EDS and TEM analysis is consistent with XRD data. XRD data shows that all the nanopowders possess hexagonal wurtzite crystal structure, TEM pictures shows the accurate size of the crystallite which is approximately coincided with XRD, UV-VIS-NIR analysis reveals the characteristic absorption edge near $375 \mathrm{~nm}$, PL spectrum shows the emission peaks relating to defects, VSM measurements reveals the Ferromagnetic nature of the $(\mathrm{Ni}$, Al) co-doped samples.

\section{Research Highlights}

1. Pure and ( $\mathrm{Ni}, \mathrm{Al})$ co-doped $\mathrm{ZnO}$ nanoparticles have been synthesized via cost effective and high yield Chemical co-precipitation method.

2. By the illustrations of TEM images and XRD calculations $(\mathrm{Ni}, \mathrm{Al})$ co-doped samples reveals lowest Crystallite size compared to Pure $\mathrm{ZnO}$ nanoparticles.

3. Based on SEM \&TEM images the morphology of the Pure, (Ni, Al) co-doped $\mathrm{ZnO}$ nanoparticles reveals heterogeneous spherical shape where as EDS spectrum shows the lack of superfluous Elements in the samples.

4. Doping of two elements (By keeping one element at constant concentration and the other at varied Concentration) could not disturb the structure of $\mathrm{ZnO}$ host lattice. All the samples reveal the characteristic ZnO Raman modes.

5. Photoluminescence (PL) spectrum shows the peaks related to defects such as oxygen vacancies (Vo) and intrinsic defects (Zni) in Zinc Oxide ( $\mathrm{ZnO})$ nanoparticles

6. All the three $(1,2,3 \mathrm{~mol} \%$ of $\mathrm{Ni}$ by keeping Al-5 mol\% at constant) concentrations shows Ferro magnetic nature, among these the 1 mol\% shows highest $\mathrm{Ms}$ and $\mathrm{Mr}$ values comparing to rest of the concentrations.

7. HRTEM illustrations of pure $\mathrm{ZnO}$ nano particles show $5 \mathrm{~nm}$ clear lattice fringes whereas doped $\mathrm{ZnO}$ nano particles show $2 \mathrm{~nm}$ clear lattice fringes.

\section{Acknowledgements}

Authors are thankful to the University Grants Commission (UGC), New Delhi, India for providing financial assistance through RFSMS program, also thankful to IIT Bombay (SAIF) for providing TEM characterization and thankful to Pondicherry university (CIF) for providing UV-Vis-NIR \& Raman characterizations.

\section{References}

[1] A. Miyake, H. Kominami, H. Tatsuoka, H. Kuwabara, Y. Nakaushi and Y. Hatanaka, J. Cryst. Growth, 214 (2000)294298.

[2] J. Hu, T. W. Odom and C. M. Lieber, Acc. Chem. Res. 32 (1999) 435-445.

[3] C. A. Mirkin, Science 286 (1999) 2095-2096.

[4] S. M. Prokes and K. L. Wang, Mater. Res. Sci. Bull. 24 (1999) 13-19.

[5] S. Nakamura, Science 281 (1998) 956-961.

[6] M. Huang, S. Mao, H. Feick, H. Yan, Y. Wu, H. Kind, E. Weber, R. Russo and P. Yang, Science 292 (2001) 1897-1899.

[7] E. Wong and P. Searson, Appl. phys. Lelt. 74 (1999 )29392941.

[8] S. Choopun, R. Vvispute, W. Noch, A. Balsamo, R. Sharma, T. Venkatesan, A. Iliadis and D. Look, Appl. phys. Lelt. 75 (1999) 3947-3949.

[9] A. sivagamsundari, R. Puzage, S. Chandra shekar, S. Ragagopan and R. Kannan, Appl. Nanosci. 3 (2013) 383388 .

[10] D. Song, A. G. Aberle and J. Xia, Appl. Surf. Sci. 195 (2002) 291-296.

[11] O. I. Lupan, S. T. Shishiyanu and T. S. Shishiyanu, Superlatt. Microstruct. 42 (2007) 375-378.

[12] T. Dietl, H. Ohno, F. Matsukura, J. Cibert and D. Ferrand, Science 287 (2000) 1019-1022.

[13] C. Karunakaran, V. Rajeswari and P. GomathiSankar, Super lattices Microstruc. 50 (2011) 234-241.

[14] M. Nirmala, P. Smitha and A. Anukaliani, Super lattice Microstrure. 50 (2011) 563-571.

[15] L Duan, W. Gao, R. Chen, Z. Fu, Solid state. Commu. 145 (2008) 479-481.

[16] J. Yang, L. Feia, H. Liua, Y. Liu, M. Gaoa, Y. Zhanga and L. Yanga, J. Alloys Compd. 509 (2011) 3672-3676. 
[17] B. Sankara Reddy, S Venkatramana Reddy, P Venkateswara Reddy and N. Koteeswara Reddy Optoelectronics Adv. Mat. Rapid communications 6 (2012) 953-959.

[18] P. Swapna and S. Venkatramana Reddy, Mechanics, Materials Science \& Engineering, (2017) ISSN 2412-5954.

[19] P Swapna and S Venkatramana Reddy, IOP Conf. Series: Materials Science and Engineering 310 (2018) 012011.

[20] P Swapna and S Venkatramana Reddy, Adv. Sci. Lett. 24 (2018) 5636-5639.

[21] A. Singhal, S. N Achary, J. Manjanna, S. Chatterjee, P. Ayyub and A. K. Tyagi, J. Phys. Chem. C 114 (2010) 3422-3430.

[22] M. Schumm, M. Koerdel, S. Muller, C. Ronning, E. Dynowska, Z. Golacki, W. Szuszkiewicz and J. Geurts, Appl. Phys. 105 (2009) 083525.

[23] P. Che, W. B. Liu, L. Guo, L. He and C. P. Chen, J. Magn. Magn. Mater. 320 (2008) 2563-2566.

[24] B. Sankara Reddy, S. Venkatramana Reddy, N. Koteeswara Reddy J Mater Sci: Mater Electron 24 (2013) 5204-5210.
[25] R. Wu, Y. Yang, S. Cong, Z. Wu, C. Xie, H. Usui, K. Kawaguchi and N. Koshizaki, Chemical Physics Letters406 (2005)457- 461.

[26] M. Ghosh and AK. Raychaudhuri. Nanotechnology 19 (2008)445704.

[27] R. Elilarassi, G. Chandrasekaran, J Mater sci: Mater Electron, springer science+Business media, (2010).

[28] S. Muthukumaran, R. Gopalakrishnan, optical materials, Elsevier, (2012).

[29] M. Kapilashrami, J. Xu, K. V. Rao and L. Belova, Processing and Application of Ceramics 4 (2010) 225-229.

[30] J. Hu, Z. Zhang, Z. Zho, H. Qin and M. Jiang, Appl. Phys. Lett. 93 (2008) 192503.

[31] M. Kapilashrami, J. Xu, V. Ström, K. V. Rao, L. Belova, Appl. Phys. Lett. 95 (2009) 033104. 